\title{
Relações amorosas ao longo das décadas: um estudo de cartas de amor
}

\author{
Caroline Carpenedo \\ Pontifícia Universidade Católica do Rio Grande do Sul \\ Sílvia Helena Koller \\ Universidade Federal do Rio Grande do Sul
}

\begin{abstract}
RESUMO
Este estudo analisa as relações amorosas desde os tempos passados até os atuais por meio da análise de cartas de amor trocadas entre casais. Para tanto foram selecionadas cartas amorosas das décadas de 40-50, 70-80 e 2000 e analisados os conteúdos das mesmas. Oito casais foram escolhidos de forma intencional, considerando-se que ambos deveriam ser originários de cidades do interior do estado e possuírem nível socioeconômico médio. Destes, dois mantinham relacionamento durante as décadas de 40-50, três casais correspondiam-se durante as décadas de 70-80, e por último, outros três casais da década de 2000. A análise das cartas permitiu visualizar que as mudanças socioculturais ocorridas nas últimas décadas influenciaram diretamente nos relacionamentos amorosos. Sendo assim, encontraramse muitas modificações nestes relacionamentos desde a década de 40-50 até a atualidade, principalmente no que se refere às atitudes do casal e a comunicação estabelecida entre estes.
\end{abstract}

Palavras-chave: casais; relacionamentos amorosos; transformações nas relações amorosas; cartas.

\begin{abstract}
Love relationship across decades: a love letters study

This study analyzes the loving relationships across the decades through the analysis of love letters. Loving letters written in the decades of 40-50, 70-80, and 2000 were selected and analyzed. Eight couples were chosen in an intentional way, and were considered that both should be original of countryside, and medium socioeconomic level. Two maintained relationship during the decades of 4050 , three couples belonged together during the decades of 70-80, and last, other three couples of the decade of 2000. The analysis of the letters allowed visualizing that some sociocultural changes happened in the last decades, influencing directly in the loving relationships. There were many changes in these relationships since the decade of 40-50 to the present time, mainly in what they refer to the couple's attitudes and the established communication among these.
\end{abstract}

Keywords: couples; loving relationships; transformations in the loving relationships; letters.

Este estudo visa a analisar as modificações relativas às relações amorosas desde os tempos passados até os atuais. Trata-se de um tema relevante a ser investigado, já que os novos papéis desempenhados por homens e mulheres têm resultado em mudanças nas configurações das relações entre os casais. Para atingir tal objetivo, foram selecionadas cartas amorosas das décadas de 40-50, 70-80 e 2000 e analisados os conteúdos das mesmas. Esta análise gera uma melhor compreensão sobre as transformações que as relações entre os casais de hoje vêm sofrendo, assim como, demonstra a adaptação necessária a estas novas realidades que surgem. Nas cartas amorosas, foram analisados os temas emergentes em cada época no contexto do casal e, acima de tudo, mostram quais os aspectos que diferem entre as relações de hoje e de antigamente.

As cartas amorosas imortalizam vivências e sentimentos do casal. Funcionam não apenas como um modo de comunicar, mas em especial de tornar presente, de substituir aquele que a escreveu - e que está ausente - pelo que está escrito (Amaral, 1948; Faur, 2001). Representa um discurso à distância. Para um casal de namorados, pode representar o papel que melhor fala ao coração para aquilo que reconforta nos momentos difíceis de saudade. A carta permanece como um "documento autêntico" e, neste sentido, para Faur (2001), seria um depósito de espontaneidade, sentimentos, experiências e emoções. Nas cartas de amor, aquele que escreve, conta histórias, concretiza intenções e estabelece significados ocultos que devem ser decifrados por aquele que lê. Partindo dessa perspectiva, reafirma Faur (2001) que, mais importante que o documento em si, é a mensagem singular que ele transmite.

As cartas denunciam formas de organização da sociedade no decorrer do tempo. Durante a Revolução Industrial, século XVIII, por exemplo, o homem tinha papel de pai e chefe de família, já a mulher deveria ser uma excelente dona-de-casa e incansável mãe. Seu trabalho não era valorizado nem remunerado. Com o passar do tempo, a capacidade reprodutiva passou a ser inerente à mulher e a ela coube, também, uma série de tarefas (trabalho doméstico) (Del Priore, 1997; Marodin, 1997; Siqueira, 1995; Von Koss, 2000). 
No século XIX, foi fortalecida e disseminada a idéia de uma dicotomia entre os gêneros (Del Priore, 1997; Silva, 2000). Homem lembraria cérebro, inteligência, razão lúcida, capacidade de decisão, enquanto que mulheres lembrariam coração, sensibilidade, sentimentos (Del Priore, 1997). A organização da família era mantida por leis estabelecidas pelo Estado e apoiadas pela Igreja (Von Koss, 2000). A relação de submissão e dominância estava na base da sociedade patriarcal.

Desde a sociedade tradicional aos dias atuais, surgiram mudanças profundas, principalmente nos âmbitos econômico, sociocultural, religioso e no contexto psicológico. No âmbito econômico, o surgimento de eletrodomésticos, dos congelados, creches e outros, muda substancialmente o modelo relacional familiar, especialmente para a mulher, nas tarefas a ela delegadas. Já o avanço científico possibilita à mulher, o domínio da sua própria sexualidade, e permite a ela prevenir-se contra uma possível gravidez, por exemplo. No âmbito sociocultural, o Movimento Feminista, década de 60, vem denunciar a persistência da desigualdade e questionar os papéis de mãe, educadora e esposa, buscando nova visão de mulher, participativa na vida familiar, social e do trabalho. Os valores religiosos perdem poder e não mais influenciam tanto na sexualidade e na continuidade do casamento. Por último, no contexto psicológico, o indivíduo pode buscar sua auto-realização pessoal, sexual e profissional (Albuquereque, 1996; Marodin, 1997).

Na década de 60, também houve progressos na área da educação superior. As escolas de graduação e as fundações começaram a estimular as mulheres a obterem Ph.Ds., oferecendo bolsas de estudo e um considerável apoio financeiro (Del Priore, 1997). A classe média expandiu-se e houve melhorias nas condições de vida das mulheres. Para Van Koss (2000), a luta pela educação para as mulheres fez com que se as diferenças entre homens e mulheres fossem diminuídas.

Todavia, como aponta Rocha-Coutinho (2000), "embora importantes transformações no papel de mulheres e homens em nossa sociedade tenham ocorrido nos últimos anos, é preciso não superestimar a profundidade dessas mudanças" (p. 67). Ainda não foram erradicadas todas as desigualdades entre os sexos, embora hoje sejam mais sutis. Mulheres convivem mutuamente com os padrões fornecidos pela sociedade antes da Revolução Feminista de 1960 e da sociedade moderna. Enquanto os conceitos não mudam completamente, essa nova mulher carrega os papéis de antes e os papéis de agora. Ela deve continuar sendo: mãe, mulher, cuidar da casa, do supermercado, do estudo e da educação dos filhos, além de estudar, disputar o mercado de trabalho com os homens, entre outros (Siqueira, 1995). Como expressa Strey (1997), a atualidade exige uma acumulação de papéis por parte das mulheres. Mesmo após todas essas mudanças na sociedade, parece que para as mulheres junto com os novos tempos, estão os velhos, lado a lado, um influenciando constantemente no outro.
Mulheres, em seus novos papéis buscaram mudanças devido às suas insatisfações pessoais. Já, o novo modelo masculino, faz com que o homem que auxilia nas atividades domésticas e no cuidado dos filhos seja, até certo ponto, fruto, não de uma insatisfação pessoal, mas uma ação desencadeada pelas alterações no papel e na posição das mulheres na sociedade. Para as mulheres, entrar no mundo do trabalho é valorizador, por outro lado, para os homens colocar-se no terreno doméstico é algo pejorativo (Rocha-Coutinho, 2000).

Nos relacionamentos entre homens e mulheres, aproximadamente na década de 50, o flerte ou o namorico (jogo de gentilezas, olhadelas, gestos, sorrisos) para os homens não causava prejuízo algum, porém a mesma situação era diferente para as moças. Nos anos dourados, essas deveriam cuidar-se para não "manchar a reputação". Além de comprometer as chances das candidatas à esposa, a prática do flerte por parte das mulheres revelava uma iniciativa feminina na conquista do homem, o que também era condenável. A iniciativa da conquista era atribuída ao homem. Entretanto, se a mulher não se casasse era considerada fracassada socialmente. Por isso as moças utilizavam estratégias antes para atrair pretendentes. Elas procuravam estar sempre de bom humor, vestiam-se bem e buscavam ser amáveis (Bassanezi, 1997; Mazzel, 1962).

Nesta mesma época, anos 50, depois de o namoro ser oficializado, o casal cumpria algumas regras: os homens deveriam buscar a moça em casa e depois trazê-la de volta. Caso a moça morasse sozinha, o rapaz não podia entrar. As contas eram sempre pagas pelos homens. Segundo Bassanezi (1997), moças de família não abusavam do álcool, de preferência não bebiam. Piadas mais provocantes eram impróprias, ou seja, a moça deveria impor respeito. O que contavam eram as aparências e o cumprimento de regras, e não a espontaneidade da moça ou sua própria vontade. $\mathrm{O}$ namoro era considerado uma etapa preparatória para o noivado e o casamento, e servia como uma fase de adaptação do casal. A namorada deveria mostrar-se prendada, recatada, atenciosa - garantias de uma futura esposa. $\mathrm{O}$ namorado interessado deveria mostrar-se sério e com plenas intenções em se casar. Deveria mostrar-se também uma pessoa responsável e capaz de sustentar uma família (Bassanezi, 1997).

$\mathrm{Na}$ década de 50 e 60, se os pais não "fizessem gosto"1 pelo casamento de seus filhos, era difícil que esse casamento se realizasse (Del Priore, 1997; Velho, 1986). As revistas da época classificavam as jovens em "moças de família" e "moças levianas" (Bassanezi, 1997, p. 37). As moças de família eram respeitadas pela sociedade da época. Elas poderiam casar-se e serem donas de casa, porém deviam manter-se virgens até o matrimônio. Às levianas tudo era negado, elas eram mal faladas e não aceitas pela sociedade.

O casamento entre famílias ricas e burguesas era usado como degrau de ascensão social ou uma forma de manutenção do status. Conforme Del Priore (1997), o papel da mulher na década de 50 e 60 era ser mãe dedicada e atenciosa. Os cuidados e a supervisão da mãe passam a ser muito valorizados nessa época. $\mathrm{O}$ 
casamento significava a independência finalmente conquistada: o estabelecimento vinha do casamento (Duby, 1989; Scott, 1992). Desde muito cedo a mulher devia ter seus sentimentos devidamente "domesticados e abafados" (Del Priore, 1997, p. 49). A própria Igreja, que permitia casamentos precoces, cuidava de mantê-los assim no confessionário.

O desquite, como reforça Bassanezi (1997), era a única possibilidade de separação oficial dos casais nos anos 60, porém, não dissolvia os vínculos conjugais e não permitia novos casamentos. As mulheres desquitadas sofriam preconceito da sociedade e a conduta moral das mulheres separadas estava constantemente sob vigilância. Com o advento da pílula, segundo Von Koss (2000), o direito da mulher de exercer atividade sexual desvinculada da procriação foi evidenciado. Esse aspecto possibilitou, então, para a mulher a separação entre sexo e casamento. Atualmente, há uma franca crise na família burguesa tradicional, uma vez que o índice de divórcios tem aumentado gradativamente. As relações amorosas ficaram parcialmente desvinculadas do casamento (Siqueira, 1995).

Não é possível dizer que, na década de 60, o amor não era considerado importante para a união conjugal, mas ele não era, certamente, o suficiente para garantir uma boa vida entre os dois. Dificuldades financeiras, diferenças de classes, problemas familiares etc., eram barreiras para as uniões fora do padrão estabelecido pela sociedade. $\mathrm{O}$ namoro não deveria durar muito tempo, pois um namoro ou noivado muito longo não era favorável à reputação de uma moça (Bassanezi, 1997; Duby, 1989). A opinião social, neste mesmo período parece ser importante para as decisões tomadas pelos jovens. O noivado já era um compromisso formal com o casamento, e, então, o casal poderia tentar avançar nas intimidades, mas sem esquecer que cabia à jovem guardar sua virgindade até o período de núpcias.

Nos anos dourados, o medo das mulheres jovens era permanecerem solteiras. Deveriam, nesse caso, tratar de preocupar-se com o próprio sustento e se conformarem em ficar sozinha, uma vez que não era permitido a elas terem aventuras amorosas ocasionais. Uma mulher com mais de 20 anos de idade, sem a perspectiva de um casamento, corria o risco de ser vista como "encalhada" (Bassanezi, 1997, p. 22). Aos 25 anos, já era considerada uma solteirona, enquanto um homem de 30 anos, solteiro e com estabilidade financeira, era considerado um bom partido.

Um estudo realizado por Rocha-Coutinho (2000) com estudantes universitários do Rio de Janeiro, de ambos os sexos, com idades variando entre 18 e 28 anos mostrou que homens e mulheres buscam encontrar um(a) parceiro(a) para constituir família. Para os participantes deste estudo, relacionamento estável exige cumplicidade, respeito, confiança, troca e companheirismo. Porém, antes da busca pelo relacionamento amoroso, tanto homens como mulheres procuram se estabelecer no campo profissional e financeiro. Nas relações estáveis, o amor é indispensável, sendo o sexo muito importante. Está presente, no caso das mulheres, a visão do "príncipe encantado" (Rocha-Coutinho, 2000, p. 76). O príncipe é aquele que respeita, que é fiel, carinhoso, companheiro, cúmplice, alguém em quem se pode confiar e contar em todos momentos. Os homens também consideram essas qualidades importantes num relacionamento amoroso. Rocha-Coutinho (2000) investigou a tomada de iniciativa em seu estudo. Nas décadas de 1950 e 1960, mulher não tomava a iniciativa do romance. Hoje em dia, o paradigma do relacionamento mudou. O tema da sexualidade é, ainda, um assunto muito controverso. Enquanto as mulheres acreditam que atualmente a virgindade não seja mais um tabu tão marcado, homens consideram importante que as suas mulheres não tenham tido muitos parceiros. A preocupação com a virgindade parece estar cedendo lugar à preocupação com a escolha da hora para iniciar a vida sexual e a do parceiro ideal para esta. Segundo os homens, se houver amor e consciência, não há impedimentos para que haja relacionamento sexual.

Após a Revolução Francesa e a industrialização, por volta de 1850 , surgiu a idéia de que o casamento deve ser o resultado de um amor romântico. Hoje em dia, quase todas as pessoas misturam romance com sexo e casamento como se fosse natural, sem ter idéia de que é uma inovação revolucionária (Lins, 1999). O ritual do casamento ainda parece ser importante, mas não fundamental. Para homens e mulheres o mais importante no relacionamento afetivo é o amor e o crescimento pessoal, que lhes dão capacidade de viver relações calcadas à base de companheirismo, cumplicidade e respeito (Calligaris, 1994). O matrimônio na sociedade contemporânea é baseado em escolhas recíprocas de afetividade, sexualidade e noções de amor, porém percebe-se que esses valores estão calcados à luz da relação dos indivíduos e suas famílias de origem (Velho, 1986).

Atualmente, as mulheres estão mais independentes. O casal deve caminhar junto, na mesma direção, mas ambos tem poder de decidir sobre o rumo a ser percorrido, ao contrário da época em que as mulheres não opinavam. O companheirismo é peça chave nos relacionamentos amorosos atuais. As diferenças entre os parceiros devem enriquecer a relação e não causar discórdia (Albuquerque, 1996). As pessoas não precisam mais se submeter a papéis preestabelecidos. Mulheres são mais livres, podem decidir se querem ou não ter filhos, casar ou não casar, investir ou não em uma carreira profissional, tomar ou não iniciativa nos relacionamentos amorosos. Elas tanto podem escolher repetir os "antigos" comportamentos esperados das mulheres como optar por atitudes mais "modernas" (Bassanezi, 1997; Rocha-Coutinho, 2000).

Segundo Lins (1999), o principal conceito que não se modificou no decorrer dos séculos é a crença de que o 'amor verdadeiro' deve ser uma adoração mútua que não se deve questionar. Porém existem diferenças entre a atualidade e os antepassados no que se refere ao sentimento de amor verdadeiro, pois a elevação deste à categoria de condição e critério do sucesso do casamento é um acontecimento recente (Souza, 1994). Até os anos 60, o casamento era concebido como uma união de dois patrimônios familiares. Os cônjuges só 
precisavam sentir compreensão e estima um pelo outro. Homens e mulheres, ainda no século XIX, não procuravam a felicidade num casamento. Casavam-se, porque isso fazia parte da necessidade social e se acontecia de serem felizes, era da ordem da sorte (Melman, 1994; Scott, 1992). A valorização da individualidade a institucionalização da família tende a perder espaço para a dimensão da vivência a dois e do amor conjugal. Esse amor de cônjuge é compreendido também no seu aspecto sexual e essas condições passam a ser reconhecidas socialmente para o sucesso do casamento.

O mito do casal perfeito, aquele que supera todas as diferenças pelo amor, tem por finalidade última a felicidade eterna. $\mathrm{O}$ amor encontra no matrimônio, na proposta de institucionalização de um laço, a esperança de que, pela palavra empenhada na presença de terceiros, seja garantido o cumprimento das promessas amorosas (Brasil, 1994). Muitas vezes esse laço institucionalizado não suporta as promessas e se rompe. Antigamente, anos 50, as pessoas que se separavam sofriam preconceito da sociedade. Atualmente mudou a maneira de avaliar o casamento: a união não precisa ser para sempre, pode acabar e as pessoas podem reconstruir suas vidas. Não existem mais garantias de amor eterno.

As relações entre os homens e mulheres estão reeditando antigos papéis para adaptá-los às novas exigências. Ambos procuram multiplicar funções, mas ainda não conseguem dividir responsabilidades (Diniz, 1999). Um relacionamento maduro, como sugere Van Koss (2000), é estabelecido entre uma mulher e um homem plenamente adultos, autônomos, independentes e complementares. $\mathrm{O}$ amor entre estes parceiros precisa atender às necessidades dos dois.

Seiffge-Krenke (2003), em estudo longitudinal realizado com 103 jovens alemães em diferentes idades $(13,15,17,21)$ pesquisou a relação que se dá entre o desenvolvimento do jovem adulto e suas relações românticas. Os resultados mostraram que as visões sobre o parceiro romântico e as características do relacionamento são diferentes em todas as idades. Aqueles que estavam namorando com 13 anos, relataram relacionamentos mais curtos e menos intensos se comparados às outras fases. A qualidade das relações amorosas, assim como o tempo de duração, foi aumentando conforme a idade. Os jovens de 21 anos demonstraram desenvolver maior intimidade e amadurecimento nas suas relações. $O$ estudo mostrou também que aqueles adolescentes que continuadamente se envolveram com experiências românticas, com um ou vários parceiros, obtiveram ganhos na qualidade das suas próprias relações românticas ao longo do tempo. Para os indivíduos com 21 anos, os aspectos como felicidade, atração física, amizade, confiança e aceitação apareceram como importantes componentes para o amor.

Mas, e o amor, o que é? Segundo Mazzel (1962), é a necessidade que o coração dos seres humanos têm de expandir-se e encontrar correspondência e retribuição em outrem. Sternberg (1986, 1997), em sua teoria triádica do amor, sugere que este consiste em três componentes: intimidade, paixão e decisão/compro-misso. A intimidade refere-se ao sentimento de proximidade, conexão e união no relacionamento amoroso. A paixão guia o romance, a atração física, a consumação do ato sexual. Nas experiências de amor romântico, as necessidades sexuais podem predominar, porém outras necessidades como auto-estima, carícia, afiliação, dominância, submissão e auto-atua-lização contribuem para a experiência da paixão. No que se refere ao componente compromisso/decisão, num primeiro momento, ocorre a decisão de um em amar o outro. Num segundo momento, ambos comprometemse em manter o amor. Os três componentes não necessariamente acontecem juntos. Uma pessoa pode amar a outra sem estar compromissado com ela. Os três componentes estão sempre em interação uns com os outros. Todos são importantes partes do relacionamento romântico, mas o grau de importância é que pode variar de uma relação à outra.

Da combinação os três componentes do amor, proposto por Sternberg $(1986,1997)$ podem derivar oito tipos de amor: 1) a falta de amor quando não há nenhum dos três componentes; 2) a simpatia quando há presença de intimidade e ausência de paixão e compromisso; 3) o amor apaixonado, cuja paixão está presente, mas os outros dois componentes não; 4) o amor vazio sem paixão nem intimidade quando ambos decidem estar junto; 5) o amor romântico na combinação de intimidade e paixão; 6) amor companheiro que deriva da intimidade juntamente com a decisão de compromisso; 7) amor ilusório pela ausência de intimidade e presença de compromisso e paixão; até

8) amor completo, quando existem todos os três componentes (Sternberg, 1986, 1997).

Sternberg (1986) ressalta que várias questões permeiam o amor, por exemplo, o sentimento de um parceiro pode ou não corresponder ao amor que o outro sente. Outra questão importante é a distinção entre triângulo de sentimento e triângulo de ação. Cada um dos três componentes do amor tem um conjunto de ações a ele associada. Por exemplo, a intimidade pode ser manifestada através da comunicação honesta. A paixão pode ser manifestada através do toque, do fazer amor. Já o compromisso manifesta-se pela fidelidade sexual, casamento, namoro e outros. O autor reafirma que as ações que expressam um componente particular do amor podem ser diferentes de pessoa para pessoa, de relacionamento para relacionamento, de uma situação para outra.

O amor da idade média foi o precursor do amor romântico moderno como novo modelo de relação entre os sexos. Conforme Von Koss (2000), a 'senhora' casada, que ocupava um lugar dominante na corte, era figura central do amor cortês. Os jovens rapazes, solteiros e de origem nobre, muitas vezes, treinados para serem cavalheiros, se apaixonavam facilmente pelas senhoras. Começava, então, o jogo do amor no qual o cavalheiro buscava de um modo refinado cativar a amada com carícias verbais ou manuais. Atualmente, é difícil achar um conceito único para amor. No dicionário, amar é definido como 
grande afeição, ternura ou paixão por alguém como praticar um ato sexual (Houaiss, 2001).

Houve época, por volta dos anos 50, que o processo para se começar um namoro era muito mais longo e encarado com mais formalidade do que hoje em dia. Inicialmente, o casal conhecia as respectivas famílias e amigos, e os avanços do contato físico demoravam a acontecer. Atualmente, não existe uma forma de os relacionamentos começarem. Os jovens querem apaixonar-se, desejam conhecer alguém que traga uma emoção mais intensa e profunda a ser sentida. Nesse sentido, jovens se relacionam com facilidade, a fim de encontrar alguém que traga prazer efêmero (Barbach \& Geisinger, 1998). Essas são as características de muitos relacionamentos passageiros - "ficar". Esta é uma expressão usada entre os jovens atualmente e que se caracteriza por relações descompromissadas ocorridas num curto período de tempo. Desde a década de 90 temos tido este tipo de relacionamento e é cada vez mais emergente na sociedade contemporânea. O ficar implica em contato físico entre duas pessoas sem que haja compromisso entre elas. A autonomia e a liberdade são extremamente valorizadas por ambas as partes.

Para as mulheres, atualmente, é mais fácil dar vazão à sua sexualidade em relações de curta duração. A virgindade não é mais tabu e a separação ou o divórcio, já são socialmente aceitos (Quintás, 1998). As mulheres adaptaram-se rapidamente a nova fórmula do "ficar". Para alguns jovens, a liberdade no relacionamento amoroso é um ponto positivo, pois podem conhecer muitas pessoas e isso permite que se façam escolhas amorosas mais seguras. As transformações históricas evidenciadas ao longo desta introdução instigaram o desenvolvimento deste trabalho que, por sua vez, objetiva analisar as modificações das relações amorosas desde as décadas de 50 e 60 até os dias atuais.

\section{MÉTODO}

Para esse estudo utilizou-se a seleção deliberada. Os casais foram escolhidos de forma intencional, considerando-se os critérios: um dos membros do casal deveria possuir correspondências do seu companheiro/a do período que se estava pretendendo estudar, ambos deveriam ser originários de cidades do interior do estado do Rio Grande do Sul e possuírem nível socioeconômico médio.

Dessa forma, participaram deste estudo oito casais. Dentre eles, apenas um caracterizou-se por serem noivos durante o período estudado (tempo em que se correspondiam) e todos os outros eram namorados. Dos oito casais que compõem a amostra, dois mantinham o relacionamento durante as décadas de 40-50 (sendo um destes o casal de noivos), três casais correspondiam-se durante as décadas de 70-80, e por último, outros três casais da década de 2000. As idades dos participantes variaram de 15 a 26 anos e a escolaridade dos mesmos abrangeu desde Ensino Médio incompleto até Ensino Superior incompleto.

Coletaram-se ao todo 11 cartas da primeira década estudada, 26 cartas da segunda década estudada e 12 cartas dos relacionamentos nos dias atuais. Todas as cartas foram digitadas e corrigiram-se eventuais dificuldades ortográficas ou de pontuação, sem que isso interferisse no conteúdo das cartas. Esse procedimento foi realizado em função de preservar os documentos originais e retorná-los aos participantes. Os nomes dos participantes foram alterados a fim de preservar o sigilo das identidades. Fez-se uma análise de conteúdo das cartas (Bardin, 1977) a fim de analisá-las. A Tabela 1 mostra as características dos participantes.

Tabela 1: Características dos casais que trocaram cartas de amor nas décadas de 40-50, 70-80 e 2000

\begin{tabular}{|c|c|c|c|c|c|}
\hline Período & Casal $\left.^{*}\right)$ & Situação & Idade & Escolaridade & N. de cartas \\
\hline \multirow{4}{*}{$\underline{40-50}$} & Francisco & \multirow{2}{*}{ namorados } & 20 & médio completo & 1 \\
\hline & Joana & & 16 & médio completo & 3 \\
\hline & João & \multirow{2}{*}{ noivos } & 25 & médio completo & 7 \\
\hline & Vitória & & 18 & médio incompleto & 0 \\
\hline \multirow{6}{*}{$\underline{70-80}$} & Ricardo & \multirow{2}{*}{ namorados } & 20 & superior incompleto & 0 \\
\hline & Cláudia & & 16 & fundamental incompleto & 9 \\
\hline & Felipe & \multirow{2}{*}{ namorados } & 26 & superior incompleto & 6 \\
\hline & Suelen & & 19 & fundamental completo & 6 \\
\hline & Guilherme & \multirow[t]{2}{*}{ namorados } & 20 & superior incompleto & 5 \\
\hline & Gabriela & & 15 & fundamental incompleto & 0 \\
\hline \multirow{6}{*}{$\underline{2000}$} & Fernando & \multirow{2}{*}{ namorados } & 19 & superior incompleto & 5 \\
\hline & Mariana & & 19 & superior incompleto & 2 \\
\hline & Rodrigo & \multirow{2}{*}{ namorados } & 24 & superior completo & 1 \\
\hline & Camila & & 20 & superior incompleto & 0 \\
\hline & Gabriel & \multirow{2}{*}{ namorados } & 22 & superior incompleto & 0 \\
\hline & Ana & & 19 & superior incompleto & 4 \\
\hline
\end{tabular}

(*) Os nomes são fictícios.

Resultados e Discussão
As cartas dos casais participantes foram submetidas a uma análise de conteúdo (Bardin, 1977). Com base nas cartas foram criadas três categorias 
temáticas para o melhor entendimento dos resultados encontrados. A primeira descreve as atitudes do casal no relacionamento, a segunda reúne os sentimentos vivenciados por eles e a última categoria refere-se à comunicação entre o casal.

A categoria atitudes do casal está dividida em duas subcategorias: submissão e religiosidade. A maioria das mulheres das décadas de 40 e 50 seguia padrões estabelecidos pela sociedade. $\mathrm{O}$ não questionamento destas regras foi entendido, neste contexto, como submissão. A noiva ou namorada deste período pouco expunha seus sentimentos particulares para o companheiro. Algumas vezes, até manifestava seus desejos nas cartas, mas não em primeira pessoa. Elas nomeavam outras pessoas como responsáveis por dizerem àquilo que elas desejavam, sob forma de amenizar o impacto de uma declaração ou exposição em seu próprio nome.

“... o baile de caipira que é pra sair terça-feira na véspera de São Pedro, o Ivo sonha com a tua presença, pois o Ivo acha que vocês dois iriam fazer miséria, o maior sucesso segundo eu calculo vai ser este." (Joana, 40/50)

Às mulheres não era permitido questionar ou interrogar. As escolhas, que deveriam ser pertinentes ao casal, geralmente eram feitas pelos homens e, elas deveriam aceitar essas condições, configurando submissão. O papel da mulher neste contexto, anos 40 e 50, era o de ser uma boa dona de casa, esposa e mãe, sem queixar-se (Del Priore, 1997; Marodin, 1997).

“... Francisco depende de você, se posso fazer vestido de pelúcia, diga-me uma coisa certa, sim?" (Joana, 40/50)

No caso de oficializarem o casamento, era o noivo quem escolhia os padrinhos, a casa onde iriam morar, os móveis que comprariam. Esta relação submissa da mulher e dominante do homem era uma condição imposta pela sociedade da época (Von Koss, 2000).

“(...) Vitória, eu já estou escolhendo os nossos padrinhos, a Dona Beatriz disse que quer ser minha madrinha." (João, 40/50)

Segundo Sternberg $(1996,1998)$, é através de atributos pessoais e experiências vividas que as pessoas interagem com os outros. A partir disto, criam-se histórias sobre o amor e os relacionamentos amorosos estão calcados nelas. A atração maior ocorre por parceiros que melhor preenchem os papéis que são criados nas histórias, uma vez que cada uma delas tem dois papéis complementares e tendem a satisfazer-se com as relações que se aproximam do ideal. Sendo assim, as histórias de amor podem predizer o tipo de relacionamento com o companheiro. Em geral, casais envolvidos por grande intimidade tendem a dividir histórias de amor parecidas e satisfazem mais completamente um ao outro (Sternberg, 1996, 2001).

Entre 40/50, as mulheres eram geralmente donas de casa e o homem era o responsável pelo sustento do lar. Nos anos seguintes, as mulheres já não eram tão submissas. Em 70/80 as mulheres começaram a questionar o que lhes era imposto. Tratando-se de um início de namoro, ainda não cabia a elas tomar atitudes, mas manifestar suas vontades. Alguns avanços já começam a aparecer e a mulher começa a responder por sua própria sexualidade (Albuquerque, 1996; Marodin, 1997).

"Ricardo, há um ano atrás, quando muito tranqüilamente falei:" tá legal "e aceitei o seu pedido, não imaginei a alegria que isso me traria." (Cláudia, referindo-se ao pedido de namoro aceito, 70/80)

Com o passar do tempo elas passam à ação, a demonstrar mais o que sentem, abandonando a atitude passiva das décadas anteriores. Estes progressos ocorrem com as mudanças sofridas pela própria sociedade patriarcal após década de 60 (Del Priore, 1997; Von Koss, 2000).

"Muitas promessas não cumpridas e vejo que nosso [namoro] chegou ao seu fim!" (Mariana, 2000)

A transmissão da religiosidade aparece com muito mais força nas cartas das décadas de 40/50 do que se comparada aos dias atuais. Naquela época, todas as leis estabelecidas pelo Estado eram apoiadas pela Igreja, e esta tinha muita força sobre o cotidiano das pessoas (Albuquerque, 1996; Marodin, 1997). A crença em Deus parecia ser um aspecto valorizado pelo outro, uma condição para que o namoro realmente vingasse.

\begin{abstract}
"Hoje levantei às seis e meia e fui em duas missas, a das seis e a das oito e agora estou aqui cantando $e$ pensando na minha Vitória, e ao mesmo tempo escrevendo uma cartinha para a minha Vitória." (João, 40/50)
\end{abstract}

A religiosidade, também, aparece nas décadas de 70/80, a fé em Deus parece ser uma fonte de esperança para que o casal suporte os momentos difíceis. Porém, já neste momento, os valores religiosos perdem poder e não mais influenciam tanto na sexualidade e na continuidade do casamento (Marodin, 1997).

"Creio em Deus, que nos dará tudo que
necessitamos para nós triunfarmos, desde que a
gente se esforce para chegarmos lá." (Felipe, 70/80)

Nenhuma das cartas referentes aos dias atuais trouxe questões religiosas. Parece que para os jovens deste período, diferentemente dos jovens dos períodos anteriores, a participação em cultos e missas não é uma prática regular. A prática religiosa parece ter perdido a sua força ao longo das décadas na faixa etária estudada, isto, porém, não significa que não haja religiosidade entre os jovens hoje em dia. 
A categoria sentimentos vivenciados pelo casal, para fins de análise, foi dividida em seis subcategorias: sentimento de pertença, sentimento de posse, vergonha, saudade, felicidade e tristeza. O sentimento de pertença corresponde à necessidade de sentir-se ligado à outra pessoa ou de fortalecer o vínculo fazendo parte da vida dela.

"Sempre que sentir vontade de conversar com alguém, lembre-se de mim. Em resumo, eu gostaria de senti-lo de vez em quando ao meu lado. E, não esqueças nunca que aqui, dentro da minha casa, você é considerado como um membro da família." (Suelen, 70/80)

Estes sentimentos exemplificam o componente intimidade da teoria triárdica do amor de Sternberg (1986). Este se refere àqueles sentimentos que promovem a conexão e a proximidade do casal. Envolvem o desejo de promover bem estar e felicidade para o companheiro amado, assim como poder contar com o outro nos momentos de necessidade. A mútua compreensão entre o casal, doar-se a si mesmo, dar e receber suporte emocional, construir uma boa comunicação, valorizar o amor de um na vida do outro, tudo isso emerge do componente intimidade. É claro que não necessariamente alguém tem de experenciar todos estes sentimentos, mas estes são alguns dos sentimentos que uma pessoa pode vivenciar quando tem intimidade com um outro alguém. O componente intimidade é o único, segundo afirma Sternberg, que pode ser encontrado em outras relações que não as amorosas, tais como relação entre amigos, pais e filhos, entre outras.

Os sentimentos de pertença e de posse apareceram em pelo menos uma carta de cada década estudada. Evidencia-se assim, que estes são sentimentos que permeiam as relações amorosas entre os casais das mais diferentes décadas estudadas. No sentimento de posse aparece o desejo de ter para si a pessoa amada e nesse sentido sentir-se "possuidor" daquele alguém. Muitas cartas trazem expressões indicando sentimento de posse.

"Saudações a minha noiva” (João, 40-50); “meu meninão.” (Cláudia, 70-80); “meu amorzinho.” (Mariana, 2000)

"Quero que entendas o quanto gosto de ti, o quanto me fazes bem, e o quanto quero e preciso ficar contigo.” (Ana, 2000)

"Eu nunca fui ' mordido', e sim fui ciumento. Esta é uma grande diferença: a pessoa só é 'mordida' quando tem o espírito possessivo e é ciumenta quando gosta." (Felipe, 70/80)

A maioria dos indivíduos, como afirma Sternberg (1986), expressa seu amor através de ações. Indivíduos expressam intimidade por outrem comunicando seus sentimentos internos, promovendo bem estar para o outro, dividindo seu tempo, seus pertences e a si mesmo, expressando empatia pelo outro, oferecendo suporte emocional e material. O ciúme é um ato que provém do amor e pode advir dos sentimentos de pertença e posse.

Outro componente da tríade de Sternberg (1986) denomina-se decisão e compromisso e consiste de dois aspectos: o primeiro diz respeito à decisão de um amar o outro e o segundo relaciona-se ao desejo de manter este amor. Estes dois aspectos não necessariamente estão juntos. A decisão de amar alguém não necessariamente implica manter este amor e vice-versa. Muitas pessoas podem estar juntas, porém sem ainda admitirem que estão se amando. Freqüentemente, porém, a decisão precede o compromisso. Os sentimentos de pertença e posse descritos nas cartas parecem estar diretamente relacionados com essa busca de compromisso com o outro. Outras formas de demonstrar compromisso podem se expressar em promessas e juramentos, através da fidelidade, mantendo a relação nos momentos difíceis, noivado e casamento. É claro que estas ações diferenciam-se de pessoa para pessoa e de situação para situação. O importante, conforme o autor, é considerar que os componentes do triângulo são expressos através de ações e estas têm diferentes efeitos sobre a relação.

\begin{abstract}
"Meu bem, eu ando tão nervosa esta semana que tem horas que não sei o que vou fazer, me passou tanta coisa pela cabeça, principalmente o que vai se realizar para nós dia 24. Parece que não é verdade não me entra na cabeça, mas seguramente que cuidarei de ti para sempre."(Joana, referindo-se a data de casamento marcada, 40/50)

"Você não acredita, mas eu ainda vou fazer esta tua cabecinha crer na minha confiança e sinceridade. Hoje é você que está insegura. E não pode sabe por que? Porque você é minha." (Felipe, 70/80)
\end{abstract}

A vergonha, assim como a submissão e a religiosidade, parecem estar presentes com mais intensidade nas cartas de 40/50. O casal, neste período, parecia ter uma preocupação maior com a privacidade. Existia um certo medo do ridículo, um temor ao julgamento dos outros, que se confundia, muitas vezes, com timidez e acanhamento. Isso tudo poderia acontecer porque a intimidade, segundo descreve Sternberg (1986) pode demorar a se estabelecer, e parece ser isto o que acontecia entre os casais da época, uma vez que os casais cumpriam certas regras antes do início de um relacionamento (Bassanezi, 1997). Outro fato é que as cartas eram o único meio de comunicação existente entre algumas cidades do interior, e elas poderiam ficar expostas à curiosidade das outras pessoas. Qualquer declaração poderia passar por um pré-julgamento da comunidade o que poderia até comprometer a "honra" da "moça", que então, se limitava a escrever o que lhe era culturalmente permitido. Todas elas tinham uma "moral" a ser respeitada pela sociedade da época (Del Priore, 1997; Velho, 1986).

"(...) quando recebi tua carta, o Ivo estava aqui na loja eu expliquei a ele mas, ele não se satisfez com que eu disse, queria a todo pano ler a carta e tanto fez até que eu mostrei, mas sem antes cortar o que 
escreveste em cima, pois isto iria me deixar bastante encabulada." (Joana, 40/50)

Desde a década de 70, as cartas passaram a trazer mais sentimentos e pensamentos por parte daqueles que as escreviam. Nos dias atuais, nota-se que os jovens se expressam com mais liberdade e menos preconceitos. Não parece haver quaisquer tabus que impeçam a exposição daquilo que querem declarar. A intimidade parece estabelecer-se muito mais rapidamente hoje entre os jovens. Estes consideram o amor, a capacidade de viver relações calcadas à base de companheirismo, cumplicidade e respeito importante num relacionamento afetivo (Calligaris, Sternberg, 1986).

"Nunca havia tido um contato com uma pessoa assim, para mim tudo é diferente, e estranho, às vezes, percebo que não lhe passo muita segurança, sou infantil, não me entrego totalmente, mas é que fico com receio de amanhã, talvez, não poder mais ao seu lado." (Ana, 2000)

A maneira como as pessoas agem demonstra como elas pensam e sentem, afirma Sternberg (1986). O próprio autoconceito afeta o comportamento das pessoas nos relacionamentos. A maneira individual como as pessoas agem é muito importante para manter o amor. Sem expressar os sentimentos, até o maior dos amores pode morrer.

A saudade foi relatada nas cartas desde as décadas de 40/50 até os dias atuais, porém, revelou-se de maneiras diferentes no decorrer dos anos. Antigamente era muito mais difícil o contato com a pessoa amada. Os meios de comunicação eram escassos e os casais comunicavam-se por cartas que levavam dias a chegar (Del Priore, 1997). Os meios de transporte eram lentos e estradas de chão dificultavam ainda mais o acesso às cidades. As cartas eram instrumentos que ajudavam o outro a lidar com a saudade que sentia.

"Mas quando chegam os sábados e domingos que vejo os outros passearem com suas namoradas ou então noivos, fico triste e a saudade me bate a porta que nem sei que rumo tomar, Nega se pudesse não te deixaria um só minuto longe de mim.” (João, 40/50)

Em 70/80, essa falta do ser amado continua evidenciada, mas nessa época os casais já começam a falar mais freqüentemente ao telefone e, também, têm mais possibilidades de se encontrarem. As restrições atribuídas pelas famílias já são menores e o casal tem mais liberdade nesta época (Bassanezzi, 1997; Del Priore, 1997).

"São exatamente 10:20hs, quando começo a te escrever. Desliguei o telefone há poucos segundos. Só tive tempo de pegar o papel e a caneta para te escrever. A letra é feia. Como te falei, estou morrendo de saudades de ti."(Guilherme, 70/80)
O recebimento das cartas do amado(a) era motivo de momentânea, mas intensa felicidade, descrita nas cartas de 40/50. A alegria era simples, bastava um pequeno gesto de amor do companheiro(a).

\begin{abstract}
"Quando chega o momento de te escrever Vitória, é um prazer para mim, mas quando chega a hora de receber as tuas cartinhas a alegria é ainda muito maior, pois nega, com o amor se compara nada, o amor é sempre o maior." (João, 40/50)
\end{abstract}

Nas décadas que se seguem, as cartas continuam sendo importantes, porém o contato com o companheiro já é mais frequiente. As cartas, na maioria das vezes, traziam relatos de atividades que os dois fizeram juntos, sendo que sua releitura poderia proporcionar a recordação daquela felicidade (Mazzel, 1962). Estudo de Sternberg (2001) mostrou que casais mais íntimos, o que pressupõe um certo grau de contato, proporcionam mais prazer um ao outro. Tal intimidade e prazer podem caracterizar felicidade.

\begin{abstract}
'Sabe, Fofo, receber cartas tuas é 'reviver', sentir o quanto é legal e importante amar, o quanto é genial dizer 'Fofo, te amo'." (Cláudia, 70/80)
\end{abstract}

Nos dias atuais, a exigência pela busca do prazer passou a ser muito maior. Um dos membros do casal começa a reivindicar a companhia do outro e momentos de lazer mais freqüentes e intensos. Alguns casais contemporâneos sofrem com dilemas da atualidade: falta tempo para relação a dois, uma vez que compromissos com trabalho, família, amigos, entre outros também demandam atenção (RochaCoutinho, 2000).

Altos e baixos nos relacionamentos amorosos são inevitáveis, e na maioria das vezes, o que mantém o casal junto nos momentos difíceis é o compromisso assumido um pelo outro (Sternberg, 1986). Esse componente é essencial para o casal atravessar momentos difíceis. O fato de o casal estar separado pela distância provocava uma profunda tristeza. Este sentimento é descrito com freqüência nas cartas das décadas de 40/50. A tristeza causada pelo afastamento físico do casal aparece, também, nas décadas seguintes, sendo que nesta subcategoria não houve profundas transformações.

\footnotetext{
"Hoje vou terminar, porque estou ainda com a cabeça cheia, eu estou levando uma vida triste $e$ abandonado, socado sempre num canto sem nem um prazo, já estou até enjoado desta vida assim, isto já é deixar de viver." (João, 40/50)
}

A categoria comunicação entre o casal no relacionamento foi dividida em duas subcategorias: estilo e assunto, que por sua vez, foram subdivididas em

subitens para melhor descrição e compreensão.

Dentro da subcategoria estilo analisou-se: estilo de linguagem, chamamento, brincadeira, fala em terceira pessoa, sedução e poesia. As expressões usadas nas 
décadas de 40/50 retratam um estilo diferente de linguagem. Gírias e palavras que hoje não mais existem eram usadas na comunicação entre os jovens.

"não desespere assim no mais, foram eles que
fizeram a peleia. "(Joana, referindo-se a uma briga,
$40-50)$
"não sei se é relaxamento teu ou alguém está
abrindo as tuas cartas, então vou te mandar um
vidro de goma rabica e envelopes." (João, refere
que mandaria cola e envelopes para não receber as
cartas de Vitória abertas, 40/50)
"O pai dela tem um auto de praça e trabalha no
centro." (João, referindo-se a profissão de taxista,
$40 / 50)$

Nas décadas de 70/80, a forma de expressão mostrou-se diferente. A linguagem passou a ser mais despojada, trazendo diferentes gírias e até palavras em outros idiomas. Nas cartas dos dias atuais o uso de analogias esteve muito presente.

"Será bacana à beça nosso findi, tira essas grilações da cabeça, tá bem? Good bye, my love." (Cláudia, 70/80)

“... as saudades conquistaram o seu direito de regozijarem-se ao som de tua doce e melodiosa voz, tão reconfortante nos crepúsculos saudosos e nostálgicos." (Fernando, 2000)

A maneira usada pelo casal para se referirem uns aos outros, denominou-se "chamamento". Neste subitem percebeu-se diferença entre as décadas de $40 / 50$ e os dias atuais. Antes, o companheiro procurava referir-se à companheira formalmente. Muitas das cartas começavam com saudações às futuras esposas. Atualmente, não existe uma regra para referirse ao outro, mas de um modo geral tudo é mais informal.

"Estimado Fred" (Joana, 40/50); "Oi, amadico" (Mariana, 2000)

Em todos os períodos estudados, algumas cartas trazem expressões descontraídas, o que denominou-se brincadeiras. Nas décadas de 70/80 e 2000, porém, ampliou-se o sentido do uso das brincadeiras. Algumas continuaram sendo utilizadas como forma de descontração, porém outras foram utilizadas para dizer de forma indireta aquilo que não tinham coragem de expressar diretamente. Sendo assim, no passado, as brincadeiras eram bastante diretas, hoje são mais indiretas e sutis, tendo muitas vezes, um segundo sentido encoberto.

"Talvez eu nunca mais volte, mas talvez eu volte no fim do ano. Por exemplo, talvez alguém venha me buscar para casar, e aí eu volto." (Suelen, 70/80)

Nas cartas das décadas de 40/50, há um modo diferente de expressão: aquele que escrevia a carta, muitas vezes, não se referia a ele mesmo em primeira pessoa, mas em terceira pessoa. $\mathrm{O}$ uso da terceira pessoa em detrimento da primeira parecia tentar neutralizar aquilo que era descrito na carta. Isso ocorria provavelmente porque, na época, não era permitido, principalmente às mulheres, expressaremse (Del Priore, 1997; Velho, 1986). A fala em terceira pessoa apareceu pouco nas décadas seguintes e não foram encontradas nas cartas atuais.

"não te escrevo agora porque estou com medo de apanhar da noiva, como tu sabes a minha noiva é muito braba e não se pode brincar com ela, se não o pau-pega." (Jõ̃o, 40/50)

A sedução, entendida aqui como a busca por um dos namorados em despertar em outrem simpatia, amor, interesse, tinha como fim último provocar desejo, deslumbramento e fascinação pelo companheiro(a). A sedução nas décadas de 40/50 era muito tímida, cheia de reservas. Geralmente buscavase alcançar apenas o primeiro objetivo acima descrito. As palavras eram delicadas e muito restritas, geralmente mandava um beijo, um abraço. Com o passar do tempo a sedução tornou-se cada vez mais provocante e liberta, trazendo muitas vezes, até conteúdos sexuais.

"Vitória, tu sabes qual é a maior vontade que tenho da minha Vitória? É de dar um beijo na boca da minha Vitória." (João, 40/50)

"Quero dançar com você, beber seus beijos ardentes, sentir seu corpo sobre o meu, sua mão macia me acariciando, quero ver nos seus olhos o desejo de me querer, de poder e ter o que ambos desejamos." (Ana, 2000)

O outro componente da tríade de Sternberg (1986) é a paixão. Numa relação amorosa, questões fisiológicas e psicológicas estão envolvidas, e na paixão a relação sexual tem grande importância. Este componente está altamente em interação com a intimidade. Por isso, em relações próximas, a paixão desenvolve-se somente após a intimidade já estar desenvolvida, uma vez que este componente ajuda substancialmente para os sentimentos de proximidade e ligação.

“...12 de junho é dia dos namorados? Não acho que não. Eu acho que todos os dias são dias para namorar e amar, 365 milhões de beijos." (Felipe, 70/80)

“...Cada vez que o telefone toca, penso que é ela. Toda vez que o interfone toca, penso que é ela! Olho para o meu celular o tempo todo para ver se não chega uma mensagem sua. Levo-o junto até ao banheiro! A todo momento posso receber algum sinal dela." (Fernando, 2000)

Houve uma época em que a paixão e os avanços do contato físico deveriam ser negados ou demoravam muito a acontecer (Diniz, 1999; Melman, 1994; Souza, 1994; Van Koss, 2000). Atualmente, os relacionamentos começam das mais variadas 
maneiras, os jovens têm procurado apaixonar-se (Barbach \& Geisinger, 1998). Por esse motivo, hoje em dia, há relacionamentos passageiros. A autonomia e a liberdade são extremamente valorizadas por ambas as partes (Lins, 1999). E a paixão, assim como a sexualidade, já podem ser assumidas pelas mulheres. A paixão pode ser demonstrada através do beijo, do abraço, do toque, do olhar, do fazer amor (Sternberg, 1986).

“...Nós precisamos tirar um atestado que os nossos pais estão de acordo, porque tu é de menor até os vinte e um anos, é preciso que os pais da noiva e os noivos assinem que estão de acordo com o casório (...) por enquanto fico a espera de um abraço bem apertadinho e um beijo." (João, 40-50)

“...O que será que significa uma pessoa ficar dois dias sem ver uma outra e já sentir saudade do beijo quente e do carinho gostoso do outro? (Suelen, 70/80)

Para Sternberg (1986), a intimidade e a paixão interagem com o compromisso. Porém, ambas podem seguir, ou seja, vir após o compromisso já estabelecido, este é o caso daqueles casamentos arranjados, muito comuns nas décadas de 40/50 (Del Priore, 1997) ou de relações próximas cuja pessoa não pode escolher o seu parceiro. O compromisso é algo que o indivíduo tem um considerável controle e pode prevenir um possível desenvolvimento de um romance extraconjugal (Sternberg, 1986). Em suma, todos os três componentes são importantes para as relações amorosas, porém sua importância difere de uma relação para outra.

"A turma aqui achou bonito o rapaz da tua irmã. A Lúcia disse que é pra ela casar logo com ele e não ser trocha que ela pode acabar sem ninguém." (João, 40/50)

Sternberg (1986) propõe que existem oito tipos de relacionamentos. Pelos dados históricos da literatura e mesmo das cartas, podemos pensar que, no passado existiam muitos relacionamentos do tipo "amor vazio". As mulheres não podiam eleger seu companheiro, devendo, portanto, acatar a escolha feita por seu pai. Relacionamentos calcados no "gostar" cuja intimidade era o único componente presente, também se via muito na época. Hoje em dia, parece não haver um tipo de relacionamento que predomina. Os casais estão imersos em uma era pós-moderna, na qual muitas regras foram quebradas e a heterogeneidade de condutas predomina.

Quanto à dinâmica dos componentes, Sternberg (1986) ressalta que no início de uma relação, o casal ainda não é capaz de predizer as ações um do outro, assim como suas emoções, motivações e cognições. A intimidade está ainda latente. Com o passar do tempo, porém, para as relações bem sucedidas, essa intimidade passa a ser manifesta e começa a aumentar as interações de um para com o outro. Ambos conseguem predizer certas ações do outro e passam a conhecerem-se melhor. Já o surgimento da paixão pode ser instantâneo, quando há atração por outra pessoa. Esses fenômenos observam-se em todas as décadas estudadas, parece ser algo inerente às relações amorosas, não variando com a época em que se viveu. Apenas a questão do compromisso se difere, pois hoje em dia vê-se que o compromisso aumenta ao longo do tempo e antigamente, algumas vezes, ele era imposto logo no início de um romance.

\begin{abstract}
"Tu escrevestes que sabe o que eu penso, mas não acertas-te nada, tu és muito boba para adivinhar as coisas, tu nem se quer com os teus sonhos não adivinhas os pensamentos do teu noivo..." (João, 40/50)

"Penso em ti a toda hora, todo dia em todo lugar. 'Sinto' (de sentir de verdade, pra valer) que nestes férias, nestes dias, este amor aumentou inúmeras vezes." (Cláudia, 70/80)
\end{abstract}

A poesia, a arte de compor versos cujo conteúdo apresenta uma visão emocional dos sentimentos, foi identificada em alguns casais das décadas de 70/80 e 2000. A expressão de sentimentos através da comunicação literária confere um caráter criativo às correspondências.

\begin{abstract}
"Minha vida não vive; felicidade é utopia; minha luta não ganha sentido; o sol que se põe me atormenta; o vinho me é ácido; o pão me é pedra." (Fernando, 2000)
\end{abstract}

Os assuntos trazidos nas cartas tratavam de lazer, trabalho e estudo, acontecimentos gerais e conflitos, sendo estes os subitens analisados nesta subcategoria. O lazer sempre foi mencionado, mas também sofreu modificações desde as décadas estudadas. Atualmente, jovens informam freqüentar festas, teatros, cinemas, shows de música. Antigamente, as festas eram chamadas reuniões dançantes nas quais tocavam

orquestras de música e as pessoas dançavam aos pares. Geralmente para que a mulher pudesse ir ao baile, ela deveria estar acompanhada do companheiro e/ou de seus pais (Del Priore, 1997; Lins, 1999). Outras formas de lazer consistiam em caminhar no parque e tomar um chimarrão. Os casais não costumavam freqüentar cinema nem teatro, porque não eram de fácil acesso.

"Francisco, o pai foi comigo no baile de São João. Esse ano tinha fogueira, fiz só onze provas, felizmente, deram como eu queria." (Joana, 40/50)

As preocupações com o trabalho e os estudos sempre apareceram relatadas nas cartas, não havendo transformações neste aspecto. As possíveis mudanças são as culturais, ou seja, os empregos mudaram e a estrutura da sociedade também, mas a rotina de trabalho continua sendo um assunto compartilhado pelo casal. 
"Nós já recebemos noventa mil sacos de soja e pretendemos comprar mais ou menos cento e oitenta mil sacos." (João, 40/50)

"Ah, ontem teve Simulão no Cursinho. Naturalmente, não estudei nada e não sei como fui, mas estou louca pra saber."(Cláudia,70/80)

"O sábado foi-me o dia mais esperado do mês de julho, afinal o pesadelo das provas acabara, restando-me apenas a tensa e ansiosa espera pelos resultados." (Fernando, 2000)

Nos anos de 40/50, os acontecimentos gerais da cidade eram sempre contados aos amados. Como as cidades do interior, naquela época, eram bastante pequenas e todos se conheciam. Todos os acontecimentos eram comentados pelas pessoas: casamentos, mortes, prisão, seqüestro, roubo, guerras. Nas décadas que se seguem, principalmente em 2000, casais continuavam a falar sobre os acontecimentos que movimentavam a cidade, mas as cartas continham pouco sobre isto.

"Ontem teve um baile no cultural e as gurias foram. A Luíza foi premiada novamente, nesta seca, tu sabes Vitória. ela se presta pra tudo. No baile saiu a dança do balão e a Luiza não teve dúvidas, venceu toda a turma, não deixou estourar o balão e de prêmio ganhou uma galinha assadinha, se tu visse a alegria dela. Hoje no café da manhã tínhamos galinha assada." (João, 40/50)

Não há relato de discussão ou conflito entre os casais dos anos de 1940 a 1950. O homem, geralmente, era quem fazia as escolhas e tomava atitudes, enquanto que à mulher cabia aceitar sem questionar (Bassanezi, 1997; Duby, 1989). Mais tarde, as brigas começam a aparecer, juntamente com as demandas do mundo moderno. As namoradas, principalmente, passaram a reivindicar mais tempo disponível aos companheiros e os conflitos, por esses e diversos outros motivos, tornaram-se mais freqüentes.

"Acho que precisamos tentar e aprender viver um sem o outro e assim repensar todo o nosso relacionamento e os nossos projetos de vida, não posso passar dedicando-me a ti como queres. Reconheço e admiro o teu enorme empenho em manter e melhorar o nosso namoro." (Fernando, 2000)

Alguns fenômenos empíricos comprovam e ajudam a entender o amor através da teoria triádica de Sternberg (1986). Os indivíduos atraem-se pelas semelhanças que encontram em suas experiências. Relações duradouras que podem chegar a casamentos felizes são aquelas em que os indivíduos têm pensamentos e valores em comum e há uma boa comunicação entre o casal. Estas relações são geralmente mais satisfatórias para ambos.

\section{Conclusão}

A análise das cartas deste estudo permitiu visualizar que as mudanças sociais e culturais ocorridas nas últimas décadas influenciaram diretamente nos relacionamentos amorosos. Sendo assim, encontraram-se muitas modificações nestes relacionamentos desde a década de 40-50 até a atualidade.

Nas atitudes do casal e na comunicação estabelecida entre estes é que estão as diferenças mais marcantes da relação das décadas de 40-50, 70-80 e 2000. No passado estes relacionamentos pareciam ter um compromisso mais sério desde o princípio. A aproximação, que deveria vir por parte do homem era lenta e desde seu início, o namoro deveria suscitar questões relacionadas ao casamento. Essa característica de romance se deu principalmente nas décadas de 40-50. Com o passar do tempo, já na década de 70-80, essas relações foram se transformando e ganhando novas roupagens. Os jovens passaram a buscar mais liberdade de escolha e de experimentação, consequientemente os relacionamentos passaram a ser menos compromissados. Nesta época, o homem ainda era quem deveria tomar partido em busca de um romance. Hoje em dia, vive-se muita liberdade nos relacionamentos, homens e mulheres tomam a iniciativa. Elas abandonaram a atitude submissa das décadas anteriores principalmente em 40-50, e além de fazerem suas escolhas, elas, atualmente, são mais independentes dos homens.

A comunicação do casal da década de 40-50 era mais formal, cheia de respeito e bastante tímida. Nas décadas seguintes, este estilo de comunicar se modificou e as cartas passaram à informalidade. Em 2000 a mulher passa a provocar o homem através das cartas, a sedução é posta sem repressão e a sexualidade é expressa. Em decorrência da época vivida, os lazeres, os acontecimentos e os conflitos entre os casais nas diferentes décadas transformaramse. Enquanto que em 40-50 casais iam a baile com orquestra, na qual dançava-se aos pares e tinha-se um horário determinado para acabar. Nos anos 70-80 e 2000 as festas parecem ser libertas, porém em 70-80 ainda havia mais regras do que hoje. As brigas entre os casais começam a aparecer somente a partir de 7080. Antes, a mulher ainda é bastante submissa, com o passar do tempo, o contexto social muda, as atitudes também e as brigas aparecem com mais intensidade.

Dentre as semelhanças dos relacionamentos nos três períodos estudados estão os sentimentos de pertença e posse. Estes sentimentos podem ser considerados intrínsecos as relações amorosas, uma vez que quando se ama alguém, se quer fazer parte da vida deste e há também o desejo de ter aquela pessoa só para si. Perceberam-se semelhanças também nas questões de trabalho e estudo. Estas estiveram presentes em todas as décadas estudadas. Esse fato se deve a estas atividades ocupar boa parte da vida das pessoas.

Apesar de este estudo buscar demonstrar quais as transformações ocorridas nas relações amorosas em diferentes décadas, sabe-se que as relações são bastante complexas, e não se tem a pretensão de 
simplificar tal complexidade. Os relacionamentos amorosos estão sempre se transformando e é impossível predizer que configurações as relações terão no futuro.

\section{Referências}

Albuquerque, A. M. (1996). Afinal, o que querem os homens? Belo Horizonte: Mazza.

Amaral, V. B. (1948). Problemas de linguagem e do estilo. Porto Alegre: Simões Lopes.

Barbach, L. \& Geisinger, D. L. (1998). Juntos para sempre: Os segredos para uma relação duradoura. São Paulo: Agora.

Bardin, L. (1977). Análise de conteúdo. Lisboa: Edições 70.

Bassanezi, C. (1997). Mulheres dos anos dourados. Em M. D. Del Priore (Org.), História das mulheres no Brasil (pp. 607-639). São Paulo: Contexto.

Brasil, M. A. C. (1994). O anel que tu me destes. Em C. Calligaris (Org.), O laço conjugal (pp. 103-110). Porto Alegre: Artes e Ofícios.

Calligaris, C. (1994). O grande casamenteiro: questionamentos psicanalíticos sobre o que nos leva a casar. Em C. Calligaris (Org.), O laço conjugal (pp. 11-23). Porto Alegre: Artes e Ofícios.

Del Priore, M. D. (Org.). (1997). História das mulheres no Brasil. São Paulo: Contexto.

Diniz, G. R. S. (1999). Homens e mulheres frente à interação casamento-trabalho: Aspectos da realidade brasileira. Em T. Feres-Carneiro (Org.), Casal e família: Entre a tradição e a transformação (pp. 39-53). Rio de Janeiro: Nau.

Duby, G. (1989). Idade média, idade dos homens: Do amor e outros ensaios. São Paulo: Companhia das Letras.

Faur, A. L. (2001). Érico Veríssimo: A epístola como expressão do literário. Dissertação de Mestrado, Curso de Dissertação de Mestrado, Pontifícia Universidade Católica do Rio Grande do Sul. Porto Alegre, RS.

Houaiss, A.; Villar, M. S. \& Franco, F. M. M. (2001). Houaiss: Dicionário da língua portuguesa. Rio de Janeiro: Objetiva.

Lins, R.N. (1999). A cama na varanda: Arejando nossas idéias a respeito de amor e sexo ( $6^{\mathrm{a}}$ ed.). Rio de Janeiro: Rocco.

Mazzel, M. (1962). Amor e felicidade (5 $5^{\text {a }}$ ed.). São Paulo: Paulinas.

Melman, C. (1994). Como ser feliz no amor, em uma lição. Em C. Calligaris (Org.), O laço conjugal (pp. 79-90). Porto Alegre: Artes e Ofícios.
Marodin, M. (1997). As relações entre o homem e a mulher na atualidade. Em M. Strey (Org.), Mulher: Estudos de gênero (pp. 9-18). São Leopoldo: Unisinos.

Quintás, A. L. (1998). A formação para o amor: Três diálogos entre jovens. São Paulo: Paulus.

Rocha-Coutinho, M. L. (2000). Dos contos de fadas aos superheróis: Mulheres e homens brasileiros reconfiguram identidades. Psicologia Clínica, 12(2), 65-82.

Scott, J. (1992). História das mulheres. Em A. Burke (Org.), A escrita da história: Novas perspectivas (pp. 63-95). São Paulo: Editora da Universidade Estadual Paulista.

Seiffge-Krenke, I. (2003). Testing theories of romantic development from adolescence to young adulthood: Evidence of a developmental sequence. International Journal of Behavioral Development, 27(6), 519-531

Silva, S. G. (2000). Masculinidade na história: A construção cultural da diferença entre os sexos. Psicologia Ciência e Profissão, 3, 8-15.

Siqueira, M. J. T. (1995). Conjugalidade e identidade de gênero: Um estudo sobre alguns aspectos contemporâneos das camadas médias brasileiras. Psicologia Argumento, 13, 31- 45.

Souza, O. (1994) Uma visita ao amor e à conjugalidade na época de Freud. Em C. Calligaris (Org.), O laço conjugal (pp. 2540). Porto Alegre: Artes e Ofícios.

Sternberg, R. J. (1986). A triangular theory of love. Psychological Review, 93(2), 119-135.

Sternberg, R. J. (1996). Love stories. Personal Relationships, 3(1), 59-79.

Sternberg, R. J. (1997). Construct validation of a triangular love scale. European Journal of Social Psychology, 27, 313-335.

Sternberg, R. J. (1998). Love is a story: A new theory of relationships. Londres: Oxford University Press.

Sternberg, R. J.; Hojjat, M. \& Barnes, M. L. (2001). Empirical tests of aspects of a theory of love as a story. European Journal of Personality, 15(3), 99-218.

Strey, M. N. (1997). A mulher, seu trabalho, sua família e seus conflitos. Em M. Strey (Org.), Mulher: estudos de gênero (pp. 59-77). São Leopoldo: Unisinos.

Velho, G. (1986). Subjetividade e sociedade: Uma experiência de geração. Rio de Janeiro: Vozes.

Von Koss, M. (2000). Feminino + masculino: Uma nova coreografia para a eterna dança das polaridades. São Paulo: Escrituras.

Enviado: 25.06 .2004 Revisado: 30.06 .2004 Aceito: 05.07.2004

\section{Nota:}

${ }^{1}$ Expressão utilizada antigamente para expressar uma aprovação, apreciação ou, até mesmo, julgar bom o parceiro amoroso da filha.

\section{Sobre as autoras:}

Caroline Carpenedo: Acadêmica de Psicologia da Pontifícia Universidade Católica do Rio Grande do Sul, bolsista CNPq. Endereço Eletrônico: ccarpenedo@redemeta.com.br

Sílvia Helena Koller: Psicóloga, Professora do Programa de Pós-Graduação em Psicologia da Universidade Federal do Rio Grande do Sul, Pesquisadora do CNPq. 
Interação em Psicologia, jan./jun. 2004, (8)1, p. 01-13 